\title{
Construct validity of RT3 accelerometer: A comparison of level-ground and treadmill walking at self-selected speeds
}

\author{
Paul Hendrick, MPhty; ${ }^{*}$ Thalia Boyd, BPhty; Oliver Low, BPhty; Kylie Takarangi, BPhty; Mike Paterson, \\ BPhty; Leica Claydon, PhD; Steve Milosavljevic, PhD \\ Centre for Physiotherapy Research, University of Otago, Dunedin, New Zealand
}

\begin{abstract}
This study examined differences in accelerometer output when subjects walked on level ground and on a treadmill. We asked 25 nondisabled participants to wear an RT3 triaxial accelerometer (StayHealthy, Inc; Monrovia, California) and walk at their "normal" and "brisk" walking speeds for 10 minutes. These activities were repeated on a treadmill using the individual speeds from level-ground walking on two occasions 1 week apart. Paired $t$-tests found a difference in RT3 accelerometer vector magnitude (VM) counts/min between the two walking speeds on both surfaces on days 1 and 2 ( $p<$ 0.001 ). Although we found no significant differences between VM counts/min on the two surfaces at normal and brisk speeds on days 1 and $2(p>0.05)$, we found wide limits of agreement between level ground and treadmill walking at both speeds. Measurement and discrimination of walking intensity employing RT3 accelerometer VM counts/min on the treadmill demonstrated reasonable validity and stability over two time points compared with level-ground walking.
\end{abstract}

Key words: accelerometer, agreement, exercise, free living, locomotor activities, physical activity, RT3 accelerometer, treadmill, walking, validity.

\section{INTRODUCTION}

The positive role of physical activity in the prevention and treatment of many noncommunicable health conditions [1-2] has led to objective measures being used more frequently in investigations of physical activity in people with pain and disability [3-5]. As many of the questionnairebased outcome measures currently employed in rehabilita- tion do not fully encompass all activities of daily living [6], a potential role exists for activity measurement as an outcome measure in rehabilitation [7] and as a tool to aid compliance with activity prescription [8-9]. Specific performance-based laboratory tests that explore the functional consequences of disability in free living have been recommended; thus, a need exists to accurately quantify mobility testing with objective measures of activity within the laboratory and to assess how these relate to activity assessment in free living [10].

The RT3 triaxial accelerometer (StayHealthy, Inc; Monrovia, California) is a waist-mounted device used to measure free-living activity within a range of populations [11-13]. Validation and reliability of the RT3 accelerometer for free-living research has been assessed under a number of laboratory-based conditions, including walking and running at standardized speeds on a treadmill [11,1417], using a shaker table [18-19], assessing various mobility tasks [3], and performing structured activities [20]. A recent study has also demonstrated the ability of the RT3 accelerometer to discriminate between a series of standardized laboratory-based activities [21]; however,

Abbreviations: $\mathrm{AVM}=$ average vector magnitude, $\mathrm{CI}=$ confidence interval, $\mathrm{CV}=$ coefficient of variation, $\mathrm{SD}=$ standard deviation, $\mathrm{VM}=$ vector magnitude.

*Address all correspondence to Paul Hendrick, MPhty; Centre for Physiotherapy Research, University of Otago, PO Box 56, Dunedin, New Zealand; +64-3-479-5428; fax: +64-3-479-8414. Email: paul.hendrick@otago.ac.nz DOI:10.1682/JRRD.2009.04.0047 
the ability of RT3 accelerometer vector magnitude (VM) counts to discriminate specific activities in free living has yet to be established.

The identification and discrimination of walking and moderate activities is the focus of much physical activity measurement in the field [22-23], primarily because of recommendations on activity and health [24]. Treadmill activities and a range of other normal activities have been employed to establish cutoff points for discriminating moderate activities within accelerometry data [25-27] and also in field studies to establish levels of free-living activity [28]. However, it is recognized that accelerometry counts depend on the activity under investigation [22] and that cutoff values will vary according to the activity employed [29]. It is therefore important to investigate the validity of using accelerometer-derived, treadmill-based activity assessments for establishing free-living cutoff points.

Extrapolating data from treadmill to level-ground walking for use in free-living activity research requires that reasonable agreement exists between accelerometry outputs for the two surfaces and at different walking speeds. Treadmill walking has been shown to be kinematically different from walking on the ground [30-31], and previous research found a significant difference in output between ground and treadmill walking using a uniaxial accelerometer [32]. However, not only does uniaxial output differ from that of a vector-summated triaxial accelerometer, but output differences also exist from the same accelerometer when comparing surfaces that have been linked to testing speed, epoch length, and step frequency [17]. A recent cross-sectional study found equivalence and agreement between RT3 accelerometer output at preset speeds on the treadmill and on level ground [33]. As clinical and research studies employ repeat measures to assess for change in participant's self-selected walking speeds, research is required to determine whether treadmill activities change over time in a manner similar to walking on level ground at participants' preferred walking speeds.

We had two aims for this study:

1. To determine differences in RT3 accelerometer outputs when comparing preferred walking speeds on level ground with preferred walking speeds on a treadmill on two occasions.

2. To determine levels of agreement between RT3 accelerometer outputs when comparing preferred walking speeds on level ground with preferred walking speeds on a treadmill on two occasions.

\section{METHODS}

\section{Participants}

We recruited a convenience sample of 25 University of Otago (Donedin, New Zealand) staff and students. Our inclusion criteria were participants (1) in good health, (2) able to walk independently $>40$ minutes at their selfselected speeds, (3) between 18 and 65 years old, (4) able to attend the initial and follow-up session, and (5) able to provide written informed consent. Our exclusion criteria were participants (1) with any history of current or past medical conditions that prevent them from walking safely $>40$ minutes, (2) unable to walk independently, (3) $<18$ or $>65$ years old, (4) unable to attend both initial and follow-up sessions, (5) unable to understand written and verbal instructions, and (6) unable to provide written informed consent.

\section{Instrumentation}

The RT3 accelerometer provides an objective measure of physical activity in "counts.” The RT3 accelerometer measures acceleration in each anatomical axis with vertical ( $x$ ), anterioposterior (y), and mediolateral (z) measurements. The square-root of the sum of squared accelerations for each axis provides a VM in counts per minute (counts/min). The RT3 accelerometer measures acceleration periodically and converts it to a digital representation, which is then processed to obtain an "activity count" and stored in the memory. The exact relationship of the activity count to the acceleration (measured in meters per second squared or $g$, where $1 g=9.81 \mathrm{~m} / \mathrm{s}^{2}$ ) is not clear [19].

We pretested the two RT3 accelerometers employed in this study using a motorized vibration table that produced a frequency of $3.3 \mathrm{~Hz}$ with a calculated mean acceleration of $0.74 \mathrm{~g}$, which is within the dynamic range of the RT3 accelerometer [19] and the range of accelerations expected during level-ground and treadmill walking [34]. We placed each RT3 accelerometer on the $x$-, $y$-, and $z$-axis on the table and tested them for 5 minutes, repeated six times on each axis. The RT3 accelerometers showed acceptable reliability across all three axes with coefficients of variation (CVs) of 0.8 to 0.9 ( $x$-axis), 1.9 to 2.2 (y-axis), and 0.9 to 3.2 (z-axis). 


\section{Procedure}

Day 1

Following informed consent, we tested all participants in self-selected comfortable footwear and clothing and asked them to use the same footwear for both the ground and treadmill walking to minimize possible gait-pattern changes. We recorded the participants' weight, height, age, sex, occupation, and ethnicity. We entered weight, height, age, and sex into the participant's profile on the RT3 accelerometer using the StayHealthy, Inc, software. We selected mode 4 (total VM counts/min) and a 1-minute epoch on the participant's profile for data collection.

We attached the RT3 accelerometer over the right lateral pelvis by placing it on the participant's trousers or skirt with a plastic clip. This method of attachment is similar to that used in free-living studies, in which participants attach the unit themselves [3]. With the RT3 accelerometer attached and turned on, we instructed each participant to walk for 10 minutes in a counterclockwise direction at their self-selected normal speed over level ground around a marked $40 \mathrm{~m}$ square consisting of $10 \mathrm{~m}$ sides, then for 10 minutes at their self-selected brisk speed. The participants performed each task individually and were not paced. Following each speed, the participant had a 5-minute seated rest. We defined normal and brisk speeds to the participant as "walking at your normal pace as if you were walking to a friend's house" and "walking at your brisk pace as if you were late for an appointment or lecture," respectively. We individually calculated the mean walking speeds for both the normal and brisk paces (kilometers per hour) using the distance walked in 10 minutes on the ground.

After a half-hour rest period, the participants then walked on the treadmill for two 10-minute periods, first at their calculated normal walking speed and then at their calculated brisk walking speed. We separated the two treadmill tasks by a 5-minute seated rest. We pressed the flag button on the RT3 accelerometer at the start and finish of each of the four 10-minute periods to provide reference points for the data analysis. At the conclusion of each participant's trial, we removed the RT3 accelerometer from the participant's hip and placed it in the "docking station" to upload data into the Stay Healthy, Inc, software.

\section{Day 2}

All participants returned to the laboratory 7 days later to repeat the two treadmill tasks, i.e., walking on the tread- mill for 10 minutes at their normal speed and 10 minutes at their brisk speed, separated by a 5-minute seated rest. Each participant wore the same RT3 accelerometer as on day 1 .

We questioned participants about any changes in their health or any new injuries they incurred in the previous week and excluded them from this second session if changes compromised their ability to complete the treadmill tasks to the same level as day 1 . We then downloaded data and imported it into a Microsoft Excel (Microsoft Corporation; Redmond, Washington) database using the StayHealthy, Inc, software.

\section{Data and Statistical Analysis}

We used a total of six 10-minute walking sessions (two ground and four treadmill) per participant $(n=25)$ for analysis. We removed the first and last minute of each 10-minute period from the analysis of both treadmill and level-ground walking data. We calculated average VM (AVM) counts/min for each walking task, i.e., normal ground, brisk ground, normal treadmill, and brisk treadmill, and used them for further analysis.

We analyzed the difference between AVM counts/min walking on level ground and walking on the treadmill at both speeds on days 1 and 2 with the paired $t$-test. We used a Bland-Altman analysis to determine the mean difference and the levels of agreement ( \pm 2 standard deviation [SD]) for AVM between walking on the treadmill and ground at the two walking speeds on days 1 and 2 [35]. We used SPSS software version 15.0 (SPSS, Inc; Chicago, Illinois) for all statistical analyses. Due to the number of paired $t$-tests employed, we set the statistical significance to $p<0.01$ to account for a possible type II error.

\section{RESULTS}

Table 1 presents the demographics and walking speeds for the 25 participants (10 males and 15 females). Table 2 presents the AVM counts/min \pm SD for participants walking on the treadmill and level ground.

\section{Speed and Surface}

Paired $t$-tests found no statistically significant difference in AVM counts/min between walking on the two surfaces at normal $(t(1)=-10.3, p=0.86$, and 124.9, $p=0.15)$ and brisk speeds $(t(1)=124.8, p=0.22$, and 115.1, $p=$ 0.35 ) on days 1 and 2, respectively (Table 3). Paired t-tests found a significant difference in AVM counts/min between 
Table 1.

Participant demographics and walking speeds $(n=25)$.

\begin{tabular}{lc}
\hline \multicolumn{1}{c}{ Variable } & Mean \pm SD (Range) \\
\hline Age $(\mathrm{yr})$ & $24.00 \pm 7.71(19-47)$ \\
Weight $(\mathrm{kg})$ & $75.00 \pm 10.83(55-100)$ \\
Height $(\mathrm{cm})$ & $174.00 \pm 7.25(163-187)$ \\
Normal Walking Speed $(\mathrm{km} / \mathrm{h})$ & $4.30 \pm 0.55(2.9-5.2)$ \\
Brisk Walking Speed $(\mathrm{km} / \mathrm{h})$ & $5.80 \pm 0.56(4.7-7.0)$ \\
\hline SD = standard deviation. & \\
\hline
\end{tabular}

Table 2.

Descriptive statistics of RT3 accelerometer total vector magnitude (VM) counts/min on level ground and treadmill at normal and brisk walking speeds.

\begin{tabular}{cclc}
\hline Day & Surface & Speed & $\begin{array}{c}\text { VM Counts/Min } \\
\text { (Mean } \pm \text { SD) }\end{array}$ \\
\hline 1 & Level Ground & Normal & $1,605 \pm 317$ \\
& & Brisk & $2,561 \pm 437$ \\
& \multirow{2}{*}{ Treadmill } & Normal & $1,616 \pm 347$ \\
& & Brisk & $2,437 \pm 638$ \\
2 & \multirow{2}{*}{ Treadmill } & Normal & $1,481 \pm 316$ \\
& & Brisk & $2,447 \pm 478$ \\
\hline SD = standard deviation. & & \\
\hline
\end{tabular}

Table 3.

Paired sample $t$-test comparing differences (mean \pm standard deviation [SD]) between RT3 accelerometer vector magnitude counts/min walking on level ground and treadmill at normal and brisk speeds from days 1 to 2 .

\begin{tabular}{lllrll}
\hline & & \multicolumn{3}{c}{ Difference } & \\
\cline { 3 - 5 } Day & Speed & \multirow{2}{*}{ Mean \pm SD } & \multicolumn{2}{c}{ 95\% CI } & p-Value \\
\cline { 3 - 5 } & & & Lower & Upper & \\
\hline 1 & Normal & $-10.3 \pm 296.3$ & -132.7 & 112.1 & 0.86 \\
& Brisk & $124.8 \pm 496.5$ & -80.1 & 329.8 & 0.22 \\
2 & Normal & $124.9 \pm 415.2$ & -46.4 & 296.4 & 0.15 \\
& Brisk & $115.1 \pm 602.5$ & -133.6 & 363.7 & 0.35 \\
\hline
\end{tabular}

Note: Significance set at $p=0.001$.

$\mathrm{CI}=$ confidence interval.

the two speeds on level ground $(t(1)=956.2, p<0.001)$ and on the treadmill on days 1 and $2(t(1)=821.0, p<$ 0.001, and 966.1, $p<0.001$ ) (Table 4).

\section{Bland-Altman Analysis}

Bland-Altman plots showed that AVM counts/min were 10 counts/min higher on the treadmill at normal speed compared with level-ground walking with the limits of agreement being 1,162 VM counts/min (Figure 1) on day 1 . Day 2 data showed wider limits of agreement at normal walking speed of 2,097 VM counts/min (Figure 2).
Table 4.

Paired sample $t$-tests comparing differences between mean RT3 accelerometer vector magnitude counts/min walking at normal and brisk speeds on level ground and treadmill from days 1 to 2 .

\begin{tabular}{|c|c|c|c|c|c|}
\hline \multirow{3}{*}{ Day } & \multirow{3}{*}{ Surface } & \multicolumn{3}{|c|}{ Difference } & \multirow{3}{*}{$p$-Value } \\
\hline & & \multirow{2}{*}{ Mean \pm SD } & \multicolumn{2}{|c|}{$95 \%$ CI } & \\
\hline & & & Lower & Upper & \\
\hline \multirow[t]{2}{*}{1} & Level Ground & $956.2 \pm 295.5$ & $1,078.1$ & 834.1 & $<0.001$ \\
\hline & Treadmill & $821.0 \pm 523.6$ & $1,037.1$ & 604.8 & $<0.001$ \\
\hline 2 & Treadmill & $966.1 \pm 356.7$ & $1,113.3$ & 818.8 & $<0.001$ \\
\hline
\end{tabular}

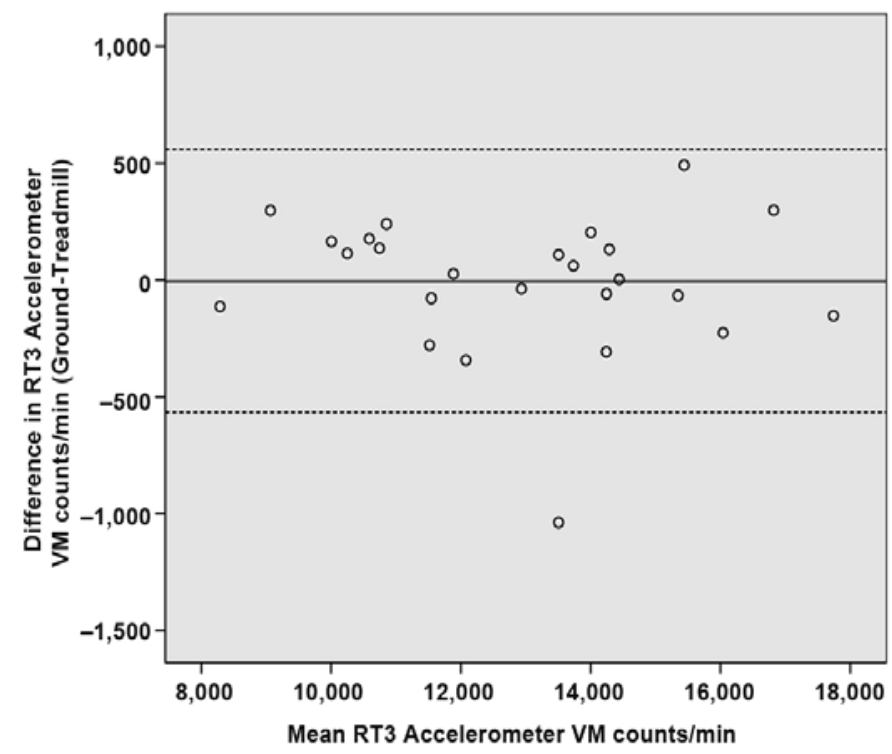

Figure 1.

Bland-Altman plot of changes in participants' normal speed (levelground walking vs treadmill walking) at same set speed on day 1 . Solid line indicates mean difference between two measures and dotted lines indicate $95 \%$ confidence interval (CI) ( \pm 1.96 standard deviation) about mean agreement. Data points above and below CI were considered outliers. $\mathrm{VM}=$ vector magnitude.

Brisk level-ground walking on the treadmill underestimated brisk level-ground walking by $125 \mathrm{VM}$ counts/min with limits of agreement of 1,946 VM counts/min on day 1 (Figure 3). The limits of agreement on day 2 were 2,360 VM counts/min (Figure 4). While it is recommended that the limits of agreement for Bland-Altman analyses be defined a priori [36], this was not done, as little published data exists on acceptable limits of agreement for accelerometry data. 


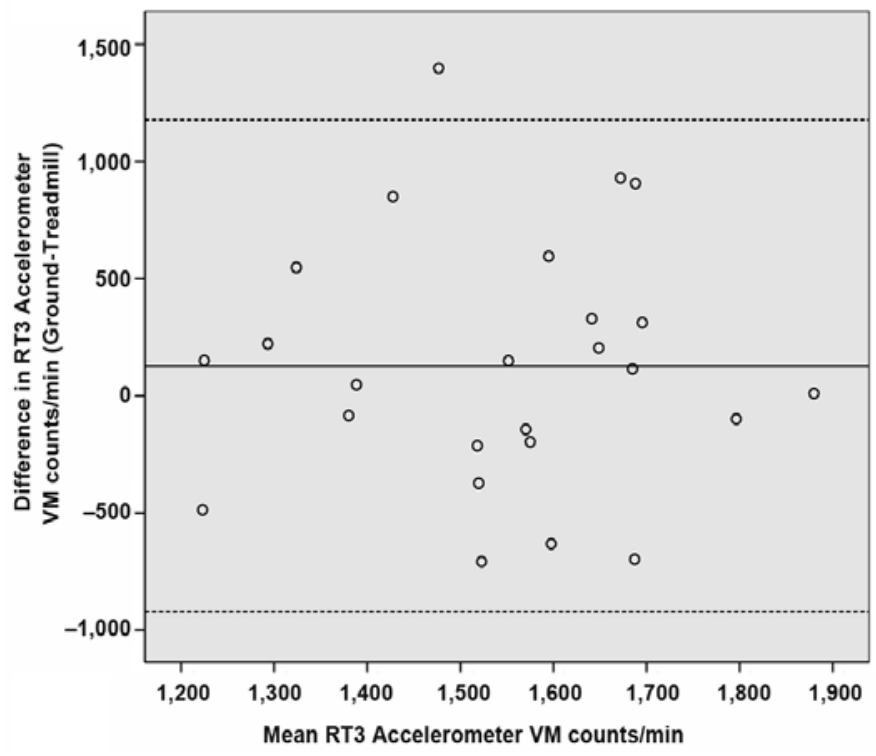

Figure 2 .

Bland-Altman plot of changes in participants' normal speed (levelground walking vs treadmill walking) at same set speed from day 1 to day 2. Solid line indicates mean difference between two measures and dotted lines indicate 95\% confidence interval (CI) ( \pm 1.96 standard deviation) about mean agreement. Data points above and below CI were considered outliers. $\mathrm{VM}=$ vector magnitude.

\section{DISCUSSION}

We found no significant differences between RT3 accelerometer VM counts/min generated from levelground walking at the participant's normal and brisk walking speeds and walking on the treadmill at the same preset speeds over days 1 and 2. A slight increase was noted in the mean difference in counts at normal speed from day 1 to day 2 with an increase in the 95 percent confidence interval (CI) about the mean also noted (Table 3). The mean difference in RT3 accelerometer VM counts/min for the brisk walking speed data remained reasonably uniform over the two measurements (Table 3). These findings are in contrast to Yngve et al., who found a statistically significant difference in uniaxial accelerometer output between level-ground and treadmill walking at participants' self-selected speeds [32]. These differences may be due to Yngve et al. [32] employing a uniaxial accelerometer, a 15-second epoch, and the use of jogging as one of the treadmill activities; others have shown that variability of RT3 accelerometer VM counts/min is speed dependent [17] and intermonitor variability increases from walking to running [15].

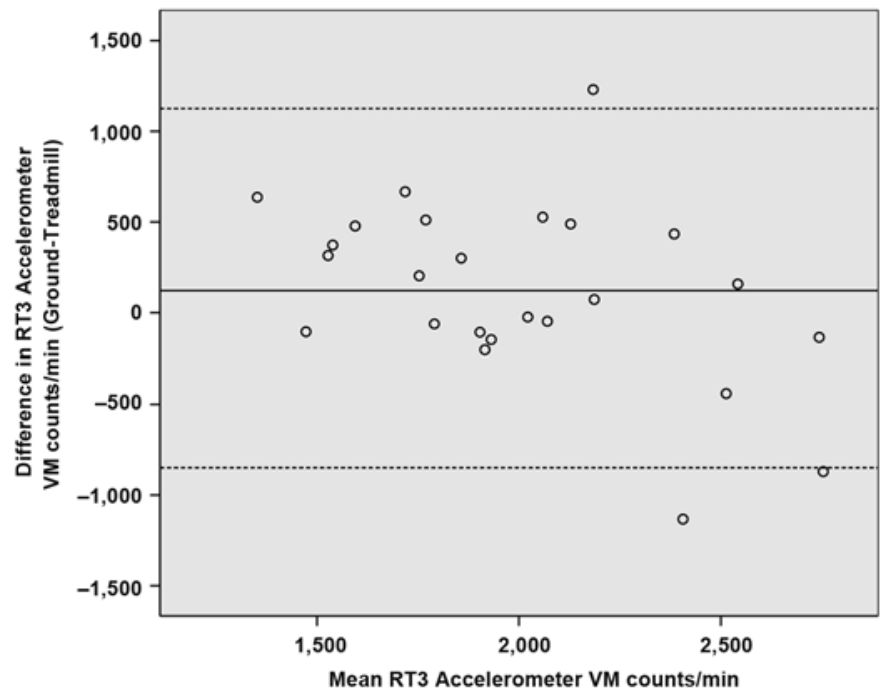

Figure 3.

Bland-Altman plot of changes in participants' brisk speed (levelground walking vs treadmill walking) at same set speed on day 1 . Solid line indicates mean difference between two measures and dotted lines indicate $95 \%$ confidence interval (CI) ( \pm 1.96 standard deviation) about mean agreement. Data points above and below CI were considered outliers.

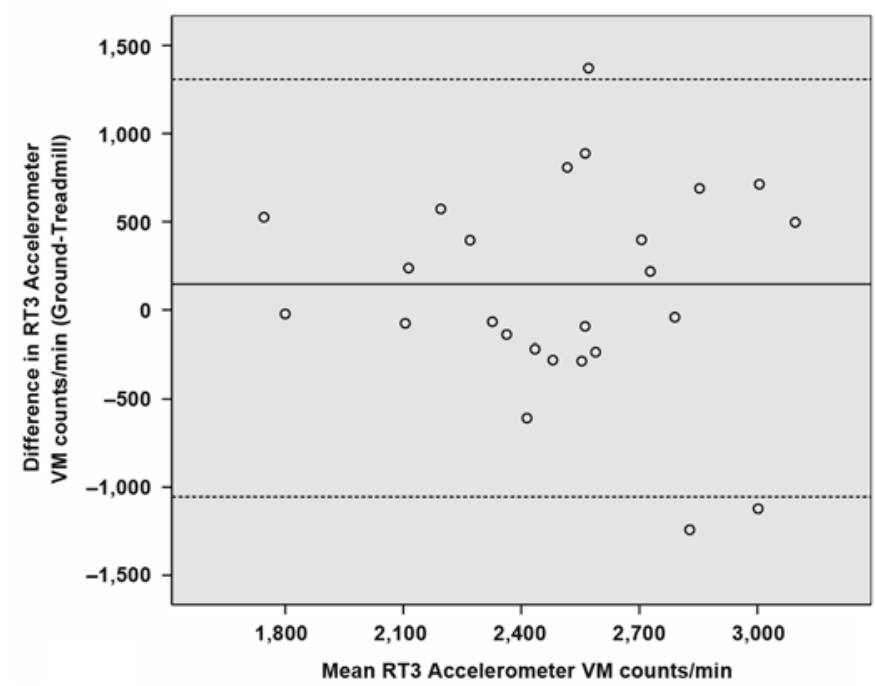

Figure 4 .

Bland-Altman plot of changes in participants' brisk speed (levelground walking vs treadmill walking) at same set speed from day 1 to day 2. Solid line indicates mean difference between two measures and dotted lines indicate 95\% confidence interval (CI) ( \pm 1.96 standard deviation) about mean agreement. Data points above and below CI were considered outliers. $\mathrm{VM}=$ vector magnitude. 
A statistically significant difference exists in RT3 accelerometer VM counts/min between the normal and brisk walking speeds on both surfaces (Table 4). This is consistent with previous research showing that the RT3 accelerometer is sensitive to changes in walking speed $[14,37]$. Previous treadmill-based studies have employed specific speeds to investigate the ability of the RT3 accelerometer to differentiate a participant's walking intensity $[17,37]$. Rowlands et al. demonstrated that RT3 accelerometer VM counts can discriminate between walking on a treadmill at $4 \mathrm{~km} / \mathrm{h}$ and $6 \mathrm{~km} / \mathrm{h}$ in adult males [14], similar to the average speeds recorded for the participants in our study. Soundy et al. developed treadmill-based cutoff values for the RT3 accelerometer based on the VM counts/ $\min ( \pm \mathrm{SD})[15]$ and later used these values to discriminate activity levels in free living [38]. Sumukadas et al. developed cutoff values based on the 95 percent CI for mean RT3 accelerometer VM counts/min in a series of laboratory-based level-ground walking and step-climbing activities [21]. These results provide support for the use of treadmill-based activity cutoff points within a nondisabled population. However, it has also been demonstrated that cutoff points derived to predict energy expenditure from laboratory-based walking activities perform poorly when applied to common household activities [22]. Also, cutoff points can vary depending on the methodology employed to derive them and differences in the estimation of freeliving activity levels [39]. Our results demonstrated wide limits of agreement between the two surfaces over both measurement periods, and therefore cutoff values are likely to depend on the testing surface. These results indicate the difficulties of categorizing continuously variable data and the potential for misclassification of physical activity data in free living. Further investigation is required to investigate the best methods to establish optimal cutoff values for free-living assessment.

A similar research study recently reported that RT3 accelerometer data from level-ground and treadmill walking was equivalent [33]. Despite this similarity, important differences also exist in these two studies. The current study assessed for differences in RT3 accelerometer data at participants' self-determined normal and brisk speeds over two separate days. In contrast, Vanhelst et al. used tests of equivalence to compare walking and running conditions at specified speeds of $4 \mathrm{~km} / \mathrm{h}, 6 \mathrm{~km} / \mathrm{h}, 8 \mathrm{~km} / \mathrm{h}$, and $10 \mathrm{~km} / \mathrm{h}$ on a single occasion [33]. Our results found no differences in treadmill-derived RT3 accelerometer output from participants' preferred walking speeds over the two testing points and also demonstrated that RT3 accelerometer output equally distinguished between participants' normal and brisk walking speeds on both surfaces. Although Vanhelst et al. found equivalence at specified speeds on a single occasion [33], they have not addressed treadmill and level-ground walking at participants' preferred walking speeds and whether their measures are stable over time. Similarly, we have not addressed equivalence and will require further research to determine this factor under both normal and brisk walking conditions on these two surfaces. Despite these differences, these two studies show that treadmill-walking data over a range of speeds are comparable with level-ground walking data when using the RT3 accelerometer.

Previous research has investigated whether a difference exists in treadmill-derived data over two time points at specified speeds $[15,17]$. Powell and Rowlands, who employed four RT3 accelerometers attached over the right or left hip of a single subject, reported no significant difference in RT3 accelerometer VM counts/min in each of the treadmill speeds over the two trials; however, intermonitor differences increased (21\%-82\%) in speeds over $6 \mathrm{~km} / \mathrm{h}$ [15]. Rowlands et al. also reported no difference in RT3 accelerometer output between trials when testing nine male runners wearing two RT3 accelerometers on a treadmill at incremental speeds from $4 \mathrm{~km} / \mathrm{h}$ to $18 \mathrm{~km} / \mathrm{h}$ [17]. The results of this study demonstrate that no difference exists in RT3 accelerometer output gathered from level-ground walking at each participant's normal and brisk speed and the same speeds on the treadmill between days 1 and 2 .

We found wide variability between the two measures (Figures 1-4), with increased variability found at participants' brisk walking speed. Increasing speed-dependent variability was also reported in a previous study investigating RT3 accelerometer output derived from a treadmill compared with level-ground walking [33]. This variability and wide limits of agreement between the surfaces could be due to kinematic differences known to exist at the hip and pelvis when comparing gait on these two surfaces [30-31]. However, more recent research found little difference in angular kinematics and vertical ground reaction forces between level-ground and treadmill walking $[31,40]$. The finding that there were only small changes in the variability of the data from days 1 to 2 is supported by kinematic research, which showed excellent repeatability between test days for three-dimensional joint kinematics at the hip and pelvis within a normal population [41]. In 
our study, level-ground walking required participants to turn $90^{\circ}$ to the left every $10 \mathrm{~m}$ with the RT3 accelerometer worn over the right hip, and this may have caused some of the variability in the two activity readings between ground and treadmill walking. It was noted that the three outliers from the data were the three fastest walkers, which suggests that when walking at higher speeds, an increased likelihood exists of greater variability between level-ground and treadmill RT3 accelerometer VM counts/min. Variability of gait parameters on a treadmill within a nondisabled population appears to depend on speed [42], age [43], and to a lesser degree, sex [44]. The relatively heterogeneous population in terms of age, walking velocities, and sex may have contributed to these findings. It is also likely that the widths of the 95 percent CIs around agreement of RT3 accelerometer VM counts/min were a function of both the relatively small sample size and also the large variability of the RT3 accelerometer VM counts/min noted at both speeds (Table 2).

The RT3 accelerometer has been previously found to have high levels of intramonitor reliability and low levels of intermonitor reliability on the treadmill $[14,17]$. Previous studies employing a mechanical vibration table have shown variable levels of interinstrument variability. Powell et al. tested 23 RT3 accelerometers at three different frequencies (2.1, 5.1, and $10.2 \mathrm{~Hz}$ ) and reported an interinstrument intraclass correlation of 0.99 and CVs for mean activity counts at each axis that ranged from 4.2 to 26.7, with the largest variability noted at the lower frequencies [19]. Consistent with these findings, higher levels of variability were found when testing across a lower range of frequencies $(1.5-2.5 \mathrm{~Hz})$, with a mean intrainstrument CV of 46.4 and interinstrument CV of 42.9 reported [45]. It is therefore recognized that reliability depends on both frequency of movement $[19,46]$ and epoch time [17]. To minimize variability due to these factors, we employed two RT3 accelerometers and each participant wore the same one on each standardized testing procedure with a 1-minute epoch, which is preferred to the shorter epoch in laboratory-based studies [17].

This study investigated the validity of the RT3 accelerometer to capture activity data on a treadmill and level ground. The variability between the RT3 accelerometer data from the two surfaces is therefore a product of both the instrument and the person, since instrument variability depends on frequency of movement, which can vary both within and between subjects and between surfaces. To evaluate the sources of such variability, we carried out preinstrument testing on the shaker table using RT3 accelerometer mode 3 to assess individual axis reliability over a 1-minute epoch, rather than the mode 4 we employed in the current study, in which samples accumulated activity counts over a 1-minute epoch. Although we found low levels of individual axis variability on pretesting, it is possible that such axis variability may differ when calculating the total VM across all three axes (mode 4). Also, as previously employed in RT3 accelerometer research, repeated instrument testing was performed on a single day to investigate instrument variability, rather than on two occasions 7 days apart, as in the current research [19,45]. Therefore, further evaluation of RT3 accelerometer variability on a shaker table employing mode 4 in a repeated measures design, as well as validation of the RT3 accelerometer in free living, would help evaluate the potential sources of such variability for free-living research. It is likely that the variation is a product of "normal" human variability in movement. Therefore the variability is likely to be increased in a free-living environment, where sustained periods of uninterrupted moderate activity are less likely to occur.

It is important for researchers and clinicians measuring activity to acknowledge and, where possible, control for the potential sources of variability in activity-related data. This process could include stratifying activity data by age and sex, adopting a standardized testing protocol with regards to activity epoch length, monitoring placement for each test speed, and familiarizing participants with the treadmill [33]. However, it should be reemphasized that the large individual variability noted did not result in an overall group mean difference in RT3 accelerometer VM counts/min between the two surfaces at either speed over the two trials.

Despite the two RT3 accelerometers showing reasonable reliability in prestudy testing, it cannot be estimated to what degree the RT3 accelerometer contributed to the variability found, and since we chose mode 4 , we were unable to explore differences and variability of the RT3 accelerometer VM counts/min across the three axes.

We attached the RT3 accelerometer over the right hip of the participants' trousers/shorts with the proprietor's clip. This method of attachment would be similar to freeliving studies, in which individuals would be responsible for attaching the RT3 accelerometer. Bouten et al. suggested that the accelerometer should be properly fixed to the body to avoid the sensor moving or jolting on the skin 
and prevent movement of clothes causing artifacts in the RT3 accelerometer output [46].

A number of participants walked with their hands on the treadmill bars for their normal walking pace on both trial days and then walked without their hands on the bars for the brisk walking pace. Owings and Grabiner found that for nondisabled individuals walking on a treadmill at their self-selected normal speed, handrail use resulted in increased stride length and decreased stride width; therefore, inconsistent handrail use in our study may have altered activity readings from the RT3 accelerometer [47]. Also, inclusion criteria did not specify familiarity with treadmill walking and this may have contributed to the variability on the treadmill between days 1 and 2 .

Practical application of these results requires further field-based research to investigate whether activity intensities in free living with the RT3 accelerometer differ significantly from laboratory-based studies. This study has shown that the RT3 accelerometer can discriminate between different walking speeds, whether the nondisabled participant is walking on level ground or on a treadmill, providing validity for the use of the treadmillbased assessment to set cutoff values for intensity and speeds of walking in the field assessment of activity. Future studies could investigate the ability of the RT3 accelerometer to discriminate moderate walking activities in free living, employing observational and/or shortterm detailed activity monitoring to assess the association with laboratory-based testing. Also, further exploration of the reasons and causes of the variability found for the measurement of activity with an RT3 accelerometer could be investigated by assessing three-dimensional motion analyses of gait characteristics and the relationship with RT3 accelerometer measurements.

Further research is required to develop tools to quantify and discriminate activity levels and to assess change in specific components of activity over time. Comparison of laboratory-based testing with free-living tests is therefore an important component of validating an activity measurement tool as a potential outcome measure in rehabilitation. Research is also required to investigate whether these results are replicated in populations with disability and mobility impairment. Such research would help to inform researchers and clinicians using treadmill and laboratory-based assessment, particularly when employed as an outcome measure to monitor changes in free-living activity levels.
These results provide information that could potentially be of use for both observational and interventionbased studies measuring activity change over time. Standardization of activity monitor validation measurements and activity level measurement in free living is a research priority [48]. This research provides clinicians and researchers with a means of potentially applying standardized treadmill assessment to level-ground walking in a laboratory as part of the process of validating an activity monitor for the measurement of physical activity in the field.

\section{CONCLUSIONS}

We found no differences in RT3 accelerometer activity counts when comparing treadmill and level-ground walking at either normal or brisk walking speeds within this cohort of nondisabled volunteers. However, we found large individual variability and poor levels of agreement between the two surfaces at both speeds. Knowledge of such variability is important when measuring physical activity, particularly when employing an activity monitor as an outcome measure and setting cutoff points for specific activity levels and/or investigating activity change over time. Within this nondisabled population, we replicated RT3 accelerometer measurements of walking pace on level ground and on the treadmill and these measurements were reasonably stable over the two time points. Thus, treadmill-derived RT3 accelerometer output has the potential to assess changes in participants' free-living walking speeds.

\section{ACKNOWLEDGMENTS}

\section{Author Contributions:}

Study concept and design: P. Hendrick.

Acquisition of data: T. Boyd, O. Low, K. Takarangi, M. Paterson. Analysis and interpretation of data: T. Boyd, O. Low, K. Takarangi, M. Paterson.

Drafting of manuscript: P. Hendrick, T. Boyd, O. Low, K. Takarangi, M. Paterson, L. Claydon, S. Milosavljevic.

Critical revision of manuscript for important intellectual content:

P. Hendrick, L. Claydon, S. Milosavljevic.

Statistical analysis: P. Hendrick.

Study supervision: P. Hendrick.

Administrative, technical, or material support: T. Boyd, O. Low, K. Takarangi, M. Paterson.

Financial Disclosures: The authors have declared that no competing interests exist. 
Funding/Support: This research was unfunded at the time of manuscript preparation.

Additional Contributions: We would like to thank all the participants and Dr. Melanie Bell (Department of Preventive and Social Medicine, University of Otago) for statistical advice.

Institutional Review: We received approval from the School of Physiotherapy Ethics Committee, University of Otago.

Participant Follow-Up: We have no plans to notify the study subjects of the publication of this article because of a lack of contact information.

\section{REFERENCES}

1. Warburton DE, Nicol CW, Bredin SS. Health benefits of physical activity: The evidence. CMAJ. 2006;174(6):801-9. [PMID: 16534088] DOI:10.1503/cmaj.051351

2. Popkin BM, Kim S, Rusev ER, Du S, Zizza C. Measuring the full economic costs of diet, physical activity and obesityrelated chronic diseases. Obes Rev. 2006;7(3):271-93. [PMID: 16866975]

DOI:10.1111/j.1467-789X.2006.00230.x

3. Hale L, Williams K, Ashton C, Connole T, McDowell H, Taylor C. Reliability of RT3 accelerometer for measuring mobility in people with multiple sclerosis: Pilot study. J Rehabil Res Dev. 2007;44(4):619-27. [PMID: 18247259] DOI:10.1682/JRRD.2005.09.0155

4. Motl RW. Physical activity and its measurement and determinants in multiple sclerosis. Minerva Med. 2008;99(2): 157-65. [PMID: 18431324]

5. Verbunt JA, Huijnen IP, Köke A. Assessment of physical activity in daily life in patients with musculoskeletal pain. Eur J Pain. 2009;13(3):231-42. [PMID: 18547847] DOI:10.1016/j.ejpain.2008.04.006

6. Mudge S, Stott NS. Outcome measures to assess walking ability following stroke: A systematic review of the literature. Physiother. 2007;93(3):189-200.

DOI:10.1016/j.physio.2006.12.010

7. Ryan CG, Gray H, Newton M, Granat MH. The convergent validity of free-living physical activity monitoring as an outcome measure of functional ability in people with chronic low back pain. J Back Musculoskelet. 2008;21(2): 137-42.

8. Robinson T, Brooke-Wavell K, Jones P, Potter J, Hardman A. Can activity monitors be used to assess compliance with walking programmes in the elderly? Int J Rehabil Res. 1995;18(3):263-65. [PMID: 7499039]

DOI:10.1097/00004356-199509000-00007

9. Morsø L, Hartvigsen J, Puggaard L, Manniche C. Nordic walking and chronic low back pain: Design of a randomized clinical trial. BMC Musculoskelet Disord. 2006;7:77. [PMID: 17014731]

DOI:10.1186/1471-2474-7-77
10. Di Iorio A, Abate M, Guralnik JM, Bandinelli S, Cecchi F, Cherubini A, Corsonello A, Foschini N, Guglielmi M, Lauretani F, Volpato S, Abate G, Ferrucci L. From chronic low back pain to disability, a multifactorial mediated pathway: The InCHIANTI study. Spine. 2007;32(26):E809-15.

[PMID: 18091475] DOI:10.1097/BRS.0b013e31815cd422

11. Hussey J, Bennett K, Dwyer JO, Langford S, Bell C, Gormley J. Validation of the RT3 in the measurement of physical activity in children. J Sci Med Sport. 2009;12(1): 130-33. [PMID: 18069065] DOI:10.1016/j.jsams.2007.09.010

12. Steele BG, Belza B, Hunziker J, Holt L, Legro M, Coppersmith J, Buchner D, Lakshminaryan S. Monitoring daily activity during pulmonary rehabilitation using a triaxial accelerometer. J Cardiopulm Rehabil. 2003;23(2):139-42. [PMID: 12668936]

DOI:10.1097/00008483-200303000-00011

13. Jacobi D, Perrin AE, Grosman N, Doré MF, Normand S, Oppert JM, Simon C. Physical activity-related energy expenditure with the RT3 and TriTrac accelerometers in overweight adults. Obesity (Silver Spring). 2007;15(4): 950-56. [PMID: 17426330$]$

DOI:10.1038/oby.2007.605

14. Rowlands AV, Thomas PW, Eston RG, Topping R. Validation of the RT3 triaxial accelerometer for the assessment of physical activity. Med Sci Sport Exerc. 2004;36(3):518-24. [PMID: 15076796]

DOI:10.1249/01.MSS.0000117158.14542.E7

15. Powell SM, Rowlands AV. Intermonitor variability of the RT3 accelerometer during typical physical activities. Med Sci Sport Exerc. 2004;36(2):324-30. [PMID: 14767258] DOI:10.1249/01.MSS.0000113743.68789.36

16. Stone MR, Esliger DW, Tremblay MS. Comparative validity assessment of five activity monitors: Does being a child matter? Pediatr Exerc Sci. 2007;19(3):291-309.

[PMID: 18019588]

17. Rowlands AV, Stone MR, Eston RG. Influence of speed and step frequency during walking and running on motion sensor output. Med Sci Sport Exerc. 2007;39(4):716-27. [PMID: 17414811]

DOI:10.1249/mss.0b013e318031126c

18. Krasnoff JB, Kohn MA, Choy FK, Doyle J, Johansen K, Painter PL. Interunit and intraunit reliability of the RT3 triaxial accelerometer. J Phys Activ Health. 2008;5(4):527-38. [PMID: 18648118]

19. Powell SM, Jones DI, Rowlands AV. Technical variability of the RT3 accelerometer. Med Sci Sports Exerc. 2003; 35(10):1773-78. [PMID: 14523319] DOI:10.1249/01.MSS.0000089341.68754.BA

20. Rothney MP, Schaefer EV, Neumann MM, Choi L, Chen KY. Validity of physical activity intensity predictions by 
ActiGraph, Actical, and RT3 accelerometers. Obesity (Silver Spring). 2008;16(8):1946-52. [PMID: 18535553] DOI:10.1038/oby.2008.279

21. Sumukadas D, Laidlaw S, Witham MD. Using the RT3 accelerometer to measure everyday activity in functionally impaired older people. Aging Clin Exp Res. 2008;20(1): 15-18. [PMID: 18283223]

22. Hendelman D, Miller K, Baggett C, Debold E, Freedson P. Validity of accelerometry for the assessment of moderate intensity physical activity in the field. Med Sci Sports Exerc. 2000;32(9 Suppl):S442-49. [PMID: 10993413] DOI:10.1097/00005768-200009001-00002

23. Bassett DR Jr, Ainsworth BE, Swartz AM, Strath SJ, O’Brien WL, King GA. Validity of four motion sensors in measuring moderate intensity physical activity. Med Sci Sports Exerc. 2000;32(9 Suppl):S471-80. [PMID: 10993417] DOI:10.1097/00005768-200009001-00006

24. Blair SN, Connelly JC. How much physical activity should we do? The case for moderate amounts and intensities of physical activity. Res Q Exerc Sport. 1996;67(2):193-205. [PMID: 8835998]

25. Brandon LJ, Ross DA, Sanford JA, Lloyd A. Predicting oxygen uptake in older adults using lower-limb accelerometer measures. J Rehabil Res Dev. 2004;41(6A):861-70. [PMID: 156585474]

DOI:10.1682/JRRD.2003.12.0176

26. Pate RR, Almeida MJ, McIver KL, Pfeiffer KA, Dowda M. Validation and calibration of an accelerometer in preschool children. Obesity. 2006;14(11):2000-2006.

[PMID: 17135617]

DOI:10.1038/oby.2006.234

27. Puyau MR, Adolph AL, Vohra FA, Butte NF. Validation and calibration of physical activity monitors in children. Obes Res. 2002;10(3):150-57. [PMID: 11886937] DOI:10.1038/oby.2002.24

28. Mota J, Valente M, Aires L, Silva P, Santos MP, Ribeiro JC. Accelerometer cut-points and youth physical activity prevalence. Eur Phys Educ Rev. 2007;13(3):287-99. DOI:10.1177/1356336X07081795

29. Nilsson A, Brage S, Riddoch C, Anderssen SA, Sardinha LB, Wedderkopp N, Andersen LB, Ekelund U. Comparison of equations for predicting energy expenditure from accelerometer counts in children. Scand J Med Sci Sports. 2008;18(5):643-50. [PMID: 18208433]

30. Alton F, Baldey L, Caplan S, Morrissey M. A kinematic comparison of overground and treadmill walking. Clin Biomech (Bristol, Avon). 1998;13(6):434-40. [PMID: 11415818] DOI:10.1016/S0268-0033(98)00012-6

31. Riley P, Paolini G, Della Croce U, Paylo K, Kerrigan D. A kinematic and kinetic comparison of overground and treadmill walking in healthy subjects. Gait Posture. 2007;26(1):
17-24. [PMID: 16905322]

DOI:10.1016/j.gaitpost.2006.07.003

32. Yngve A, Nilsson A, Sjostrom M, Ekelund U. Effect of monitor placement and of activity setting on the MTI accelerometer output. Med Sci Sport Exerc. 2003;35(2):320-26. [PMID: 12569223]

DOI:10.1249/01.MSS.0000048829.75758.A0

33. Vanhelst J, Zunquin G, Theunynck D, Mikulovic J, BuiXuan G, Beghin L. Equivalence of accelerometer data for walking and running: Treadmill versus on land. J Sports Sci. 2009;27(7):669-75. [PMID: 19424900] DOI:10.1080/02640410802680580

34. Zijlstra W, Hof AL. Assessment of spatio-temporal gait parameters from trunk accelerations during human walking. Gait Posture. 2003;18(2):1-10. [PMID: 14654202] DOI:10.1016/S0966-6362(02)00190-X

35. Bland JM, Altman DG. Statistical methods for assessing agreement between two methods of clinical measurement. Lancet. 1986;1(8476):307-10. [PMID: 2868172]

36. Mantha S, Roizen MF, Fleisher LA, Thisted R, Foss J. Comparing methods of clinical measurement: Reporting standards for Bland and Altman analysis. Anesth Analg. 2000;90(3):593-602. [PMID: 10702443 DOI:10.1097/00000539-200003000-00018

37. King GA, Torres N, Potter C, Brooks TJ, Coleman KJ. Comparison of activity monitors to estimate energy cost of treadmill exercise. Med Sci Sport Exerc. 2004;36(7):1244-51.

[PMID: 15235333] DOI:10.1249/01.MSS.0000132379.09364.F8

38. Soundy A, Taylor A, Faulkner G, Rowlands A. Psychometric properties of the 7-day physical activity recall questionnaire in individuals with severe mental illness. Arch Psychiatr Nurs. 2007;21(6):309-16. [PMID: 18037441] DOI:10.1016/j.apnu.2007.03.001

39. Guinhouya CB, Hubert H, Soubrier S, Vilhelm C, Lemdani M, Durocher A. Moderate-to-vigorous physical activity among children: Discrepancies in accelerometry-based cutoff points. Obesity. 2007;14(5):774-77. [PMID: 16855185] DOI:10.1038/oby.2006.89

40. Parvataneni K, Ploeg L, Olney SJ, Brouwer B. Kinematic, kinetic and metabolic parameters of treadmill versus overground walking in healthy older adults. Clin Biomech (Bristol, Avon). 2009;24(1):95-100. [PMID: 18976839]

DOI:10.1016/j.clinbiomech.2008.07.002

41. Growney E, Meglan D, Johnson M, Cahalan T, An K. Repeated measures of adult normal walking using a video tracking system. Gait Posture. 1997;6(2):147-62. DOI:10.1016/S0966-6362(97)01114-4

42. Jordan K, Challis JH, Newell KM. Walking speed influences on gait cycle variability. Gait Posture. 2007;26(1): 128-34. [PMID: 16982195] DOI:10.1016/j.gaitpost.2006.08.010 
43. Kang HG, Dingwell JB. Separating the effects of age and walking speed on gait variability. Gait Posture. 2008;27(4): 572-77. [PMID: 17768055]

DOI:10.1016/j.gaitpost.2007.07.009

44. Barrett R, Noordegraaf MV, Morrison S. Gender differences in the variability of lower extremity kinematics during treadmill locomotion. J Mot Behav. 2008;40(1):62-70. [PMID: 18316297] DOI:10.3200/JMBR.40.1.62-70

45. Esliger DW, Tremblay MS. Technical reliability assessment of three accelerometer models in a mechanical setup. Med Sci Sport Exerc. 2006;38(12):2173-81. [PMID: 17146326] DOI:10.1249/01.mss.0000239394.55461.08

46. Bouten CV, Sauren AA, Verduin M, Janssen JD. Effects of placement and orientation of body-fixed accelerometers on the assessment of energy expenditure during walking. Med
Biol Eng Comput. 1997;35(1):50-56. [PMID: 9136191$]$ DOI:10.1007/BF02510392

47. Owings TM, Grabiner M. Variability of step kinematics in young and older adults. Gait Posture. 2004;20(1):26-29. [PMID: 15196516]

DOI:10.1016/S0966-6362(03)00088-2

48. Ward DS, Evenson KR, Vaughn A, Rodgers AB, Troiano RP. Accelerometer use in physical activity: Best practices and research recommendations. Med Sci Sports Exerc. 2005;37(11 Suppl):S582-88. [PMID: 16294121$]$ DOI:10.1249/01.mss.0000185292.71933.91

Submitted for publication April 16, 2009. Accepted in revised form December 8, 2009. 
